\title{
Impact of Asymptomatic Carotid Artery Disease on Cognitive Functions in Patients Undergoing Off-pump Coronary Artery Bypass Grafting with and without Near-infrared Spectroscopy Monitoring and Intervention Intraoperatively
}

\author{
S Umesh ${ }^{1}$, Vinayak B Nayak ${ }^{2}$, Sahajananda Hiremathada ${ }^{3}$
}

\begin{abstract}
Background: Postoperative cognitive dysfunction (POCD) is one of the known complications after cardiac surgeries. The incidence of cognitive dysfunction varies considerably but may be as high $50-70 \%$ at 1 week after surgery, declining to 30-50\% after 2 months. Carotid artery atherosclerosis is a major risk factor for stroke and subsequent cognitive impairment. Near-infrared spectroscopy (NIRS) is a system used for monitoring the activity of the brain.

Materials and methods: Forty-three patients with asymptomatic carotid artery lesion (>70\%) undergoing elective off-pump coronary artery bypass (OPCAB) underwent preoperative and postoperative neuropsychological evaluations with the Montreal cognitive assessment (MoCA) score. The patients were randomized to receive or not to receive neuromonitoring with NIRS and subsequent management according to an algorithm. Twentyone patients received NIRS monitoring and were managed accordingly and twenty-two patients did not receive NIRS monitoring and management. Results: There was no statistically significant difference in the incidence of POCD between the groups that did or did not receive neuromonitoring and subsequent management based on NIRS at 1 hour, 24 hours, and 1 week post-extubation.

Conclusion: Neuromonitoring with NIRS and subsequent management does provide a systematic way of troubleshooting problems of cerebral desaturation. However, it has not shown any statistically significant difference in the MoCA scores taken at 1 hour, 24 hours, and 1 week post-extubation.

Keywords: Carotid lesion, Montreal cognitive assessment, Near-infrared spectroscopy, Off pump coronary artery bypass.

The Journal of Medical Sciences (2019): 10.5005/jp-journals-10045-00116
\end{abstract}

\section{INTRODUCTION}

The POCD is one of the complications after cardiac surgery. The incidence of cognitive dysfunction varies considerably but may be as high $50-70 \%$ at 1 week after surgery, declining to $30-50 \%$ after 2 months. ' Socioeconomic implications of POCD are profound; they include loss of independence, extranursing care, and a high rate of discharge to long-term care. ${ }^{2}$ Carotid artery atherosclerosis is a major risk factor for stroke and subsequent cognitive impairment. ${ }^{1,3} \mathrm{NIRS}$ is a system used for monitoring the activity of the brain. A randomized prospective study was done on the effects of NIRS on the neurocognitive functions in patients with asymptomatic carotid artery disease undergoing on-pump coronary artery bypass grafting (CABG). ${ }^{4}$ The results had been promising. We wanted to know the effect of NIRS monitoring and intervention on OPCAB grafting in patients with asymptomatic carotid artery disease.

The purpose of this study is to assess if preventing significant cerebral desaturation intraoperatively in patients with asymptomatic carotid artery disease helps reduce the occurrence of early POCD after OPCAB surgeries.

\section{Materials and Methods}

Type of study: Clinical study. Setting: It is a hospital-based study done at Sri Jayadeva Institute of Cardiovascular Sciences, Bengaluru.

\begin{abstract}
1,2Department of Anaesthesiology, Sri Jayadeva Institute of Cardiovascular Sciences, Bengaluru, Karnataka, India

${ }^{3}$ Department of Anaesthesiology, RajaRajeswari Medical College and Hospital, Bengaluru, Karnataka, India

Corresponding Author: Vinayak B Nayak, Department of Anaesthesiology, Sri Jayadeva Institute of Cardiovascular Sciences, Bengaluru, Karnataka, India, Phone: +91 9738403525, e-mail: drvinayaknayak88@gmail.com

How to cite this article: Umesh S, Nayak VB. Impact of Asymptomatic Carotid Artery Disease on Cognitive Functions in Patients Undergoing Off-pump Coronary Artery Bypass Grafting with and without Nearinfrared Spectroscopy Monitoring and Intervention Intraoperatively. J Med Sci 2019;5(2):43-48.
\end{abstract}

Source of support: Nil

Conflict of interest: None

Source of data: Patients admitted for elective OPCAB surgeries at Sri Jayadeva Institute of Cardiovascular Sciences and Hospital.

\section{Sample Size}

The calculated sample size for this study is 16 per group with loss to follow up of $10 \%$, a error $=5 \%, z$ value $=1.96, \beta$ error $=10 \%$, $z$ value $=1.28$. We felt that it would be appropriate to take 25 patients per group with a total of 50 patients. Fifty patients were evaluated. 
The study populations were divided into two groups of 25 patients each. Twenty-five patients were evaluated in each group, three patients were excluded in the non-NIRS group and four patients were excluded in the NIRS group as they were on pump coronary artery bypass surgeries.

Group N: $(n=21)$ : received NIRS monitoring intraoperatively. Group 0: $(n=22)$ : did not receive NIRS monitoring intraoperatively.

\section{Sampling Procedure}

The study was conducted on patients undergoing elective coronary artery bypass surgeries at Sri Jayadeva Institute of Cardiovascular Sciences and Hospital. All the patients falling under inclusion criteria were randomized by computer-generated randomization.

\section{Study Instrument}

A predesigned and pretested proforma was used to collect information. The cognitive assessment was done preoperatively and postoperatively using MoCA and the patients were scored accordingly.

\section{Method of Collection of Data Inclusion Criteria}

Patients belonging to American Society of Anesthesiologists (ASA) physical status I-IV aged between 40 years and 70 years, with asymptomatic carotid atherosclerosis and with lesions $>70 \%$ as evidenced by carotid Doppler who underwent elective OPCAB surgeries under general anesthesia.

\section{Exclusion Criteria}

- Symptomatic carotid artery disease or patients with $>70 \%$ lesions in carotid arteries

- Patients with a history of cerebrovascular accident or head injury

- Patients with a history of seizure disorder

- Patients with a history of psychiatric disorder

- Patients who require to be managed on pump during the course of surgery

- Patients who have undergone surgeries on carotid artery

- Significant visual, hearing, or speech disturbances

- Patients who were on drugs which cause cognitive dysfunction

- Emergency procedures

\section{Methods}

After the approval of the Institutional Ethical Committee, 50 patients scheduled to undergo elective OPCAB surgeries were enrolled in the study. All patients who met the inclusion criteria underwent a thorough preanesthetic evaluation. The cognitive assessment was performed using the MoCA test by a resident anesthesiologist not involved in the study and preoperative scores were documented. A written informed consent was taken from the patients. Patients were randomized in two groups by a computergenerated list: group N (patients receiving NIRS monitoring) and group 0 (patients not receiving NIRS monitoring). All patients were kept nil per oral overnight. The patients were taken to the operating room and standard monitors were connected which include electrocardiogram (ECG), arterial line, pulse oximetry, and NIRS monitor (in patients who will be receiving NIRS monitoring). Baseline vital parameters were documented. The patients were preoxygenated for 3 minutes. Anesthesia was induced with titrated doses of propofol IV and fentanyl $5 \mu \mathrm{g} / \mathrm{kg}$ IV, after confirming the ability to mask ventilate, vecuronium $280.1 \mathrm{mg} / \mathrm{kg}$ IV was administered. The patient was mask ventilated with oxygen and isoflurane (1-2\%) for 3 minutes, following which the trachea was intubated with an appropriate size endotracheal tube. After confirming that bilateral equal air entry, the endotracheal tube was secured. The patient was connected to a ventilator with appropriate ventilatory settings. The anesthesia was maintained with oxygen, air, and isoflurane (1-2\%) with controlled ventilation. Temperature probe and nasogastric tube were inserted and secured. The right internal jugular vein was cannulated and double-lumen central venous catheter and pulmonary artery catheter were inserted. A femoral arterial line was secured. The urinary catheter was inserted. Analgesia and muscle relaxation will be maintained with intermittent fentanyl $1 \mu \mathrm{g} / \mathrm{kg}$ IV and supplemental doses of vecuronium $0.02 \mathrm{mg} / \mathrm{kg} \mathrm{IV}$, respectively. A cerebral oxygen desaturation $>20 \%$ from the baseline was considered significant. In the case of significant cerebral desaturation, corrective measures were taken as per the Flowchart 1. Postoperatively, the patient was subjected to the MoCA test by the same anesthesiology resident who had evaluated the patient preoperatively and the cognitive function was evaluated at 1 hour, 24 hours, 48 hours, and 1 week postextubation. The anesthesiology resident who performs the test was unaware if NIRS was used intraoperatively or not. The scores were noted. The maximum score to get from this test is 30 . According to this, 26 points and above were evaluated as normal, between 19 and 25 points are evaluated as a mild cognitive disorder, and below 19 are evaluated as serious cognitive disorders. 29 statistical analyses of the data obtained were done using the paired ' $t$ ' test or the Wilcoxon-signed rank test for intergroup comparison and the independent sample $t$ test or the Mann-Whitney $U$ test for intragroup comparison. A $p$ value of less than 0.05 was taken as statistically significant (Tables 1 to 5 ).

\section{Discussion}

In our study, we evaluated 50 patients with asymptomatic carotid artery disease with lesion $>70 \%$ who were to undergo OPCAB grafting under general anesthesia. All the patients underwent neuropsychological assessment preoperatively and postoperatively by means of the MoCA score. Out of these, 21 patients received NIRS monitoring and management (group $\mathrm{N}$ ) and 22 patients did not receive NIRS monitoring (group 0 ). Seven patients were excluded from the study as they underwent on pump CABG. Out of a total score of 30 , MoCA score $\geq 26$ was considered to be normal, 19-25 were considered to have mild cognitive dysfunction, and less than 19 were considered to have severe cognitive dysfunction.

\section{POCD}

The groups were evaluated with respect to various factors that could potentially confound the results. There were no significant differences between the groups with regard to their demography, medical history, or intraoperative variables. The groups were evenly matched (as evidenced by the nonsignificant " $p$ " value between the groups) with regard to age, gender, height, weight, BMI, education, diabetes mellitus (DM), hypertension (HTN), smoking, COPD, renal insufficiency, preoperative MoCA scores, number of grafts, and time taken for grafting (Tables 1 to 3 ).

\section{POCD at 1 Hour Post-extubation}

In group 0 , out of 22 patients, 8 patients (36\%) had no POCD and 14 patients (63\%) had mild POCD; however, none of the patients 
Flowchart 1: Algorithm to manage cerebral desaturation

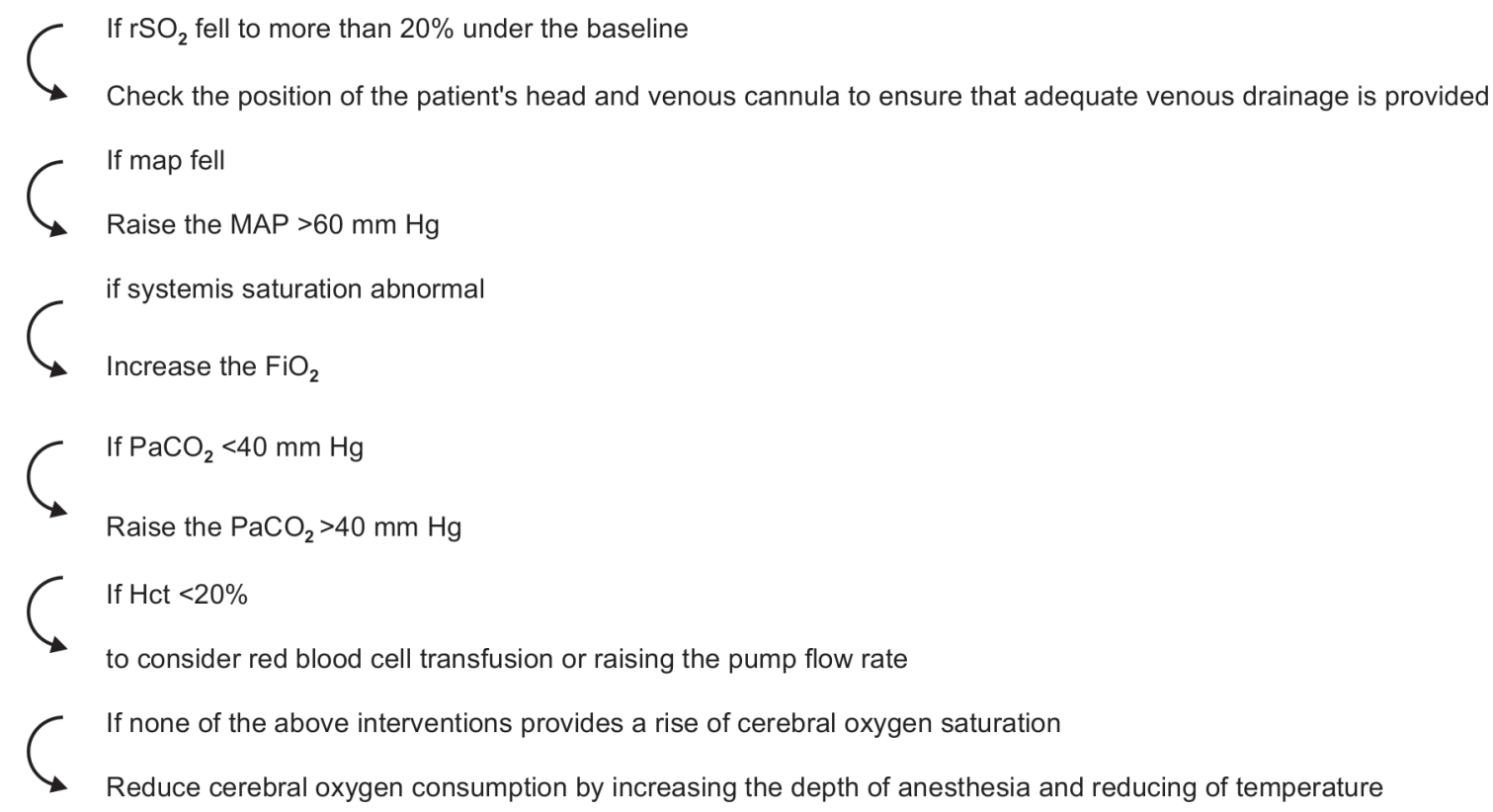

Table 1: Demographic variables between the study group and the control group

\begin{tabular}{|c|c|c|c|c|c|c|c|c|c|c|}
\hline & \multirow[b]{2}{*}{ Group } & \multirow[b]{2}{*}{$N$} & \multirow[b]{2}{*}{ Mean } & \multirow[b]{2}{*}{$S D$} & \multirow{2}{*}{$\begin{array}{l}\text { Mean } \\
\text { difference }\end{array}$} & \multicolumn{2}{|c|}{$95 \% \mathrm{Cl}$ of the difference } & \multirow[b]{2}{*}{$t$} & \multirow[b]{2}{*}{$d f$} & \multirow[b]{2}{*}{$p$ value } \\
\hline & & & & & & Lower & Upper & & & \\
\hline \multirow[t]{2}{*}{ Height $(\mathrm{cm})$} & Non-NIRS & 22 & 153.41 & 9.98 & -0.21 & -6.01 & 5.59 & -0.07 & 41 & 0.94 (NS) \\
\hline & NIRS & 21 & 153.62 & 8.78 & & & & & & \\
\hline \multirow[t]{2}{*}{ Weight } & Non-NIRS & 22 & 56.91 & 9.17 & 0.05 & -5.28 & 5.38 & 0.02 & 41 & 0.98 (NS) \\
\hline & NIRS & 21 & 56.86 & 8.06 & & & & & & \\
\hline \multirow[t]{2}{*}{ BMI } & Non-NIRS & 22 & 24.20 & 3.43 & 0.10 & -1.89 & 2.10 & 0.10 & 41 & 0.92 (NS) \\
\hline & NIRS & 21 & 24.09 & 3.02 & & & & & & \\
\hline \multirow[t]{2}{*}{ Age (years) } & Non-NIRS & 22 & 60.05 & 6.66 & -0.15 & -4.06 & 3.77 & -0.08 & 41 & 0.94 (NS) \\
\hline & NIRS & 21 & 60.19 & 6.01 & & & & & & \\
\hline
\end{tabular}

Independent sample $t$ test

$p<0.05$, statistically significant; $p>0.05$, nonsignificant, NS

Study group: with NIRS monitoring and management; control group: without NIRS monitoring and management

had severe POCD. The corresponding figures in group $\mathrm{N}$ were 8 patients (38\%) with no POCD and 13 patients (61\%) had mild POCD (Fig. 1).

At the outset, it appears that not only the number of patients who developed POCD was less in group $\mathrm{N}$ but the severity is also less. However, this difference is not statistically significant as evidenced by the " $p$ " value.

\section{POCD at 24 Hours Post-extubation}

In group 0 at 24 hours post-extubation, 12 patients (54\%) had no POCD, whereas 10 patients (45\%) had mild POCD. In group N, 14 patients (66\%) had no POCD, whereas 7 patients (33\%) had mild POCD. However, both the groups did not have patients with severe POCD. Again at 24 hours, the patients in group N had better MoCA scores and even the patients having mild POCD were lesser in group N (Tables 4A and B).

However, this apparent improvement in group $\mathrm{N}$ too was not statistically significant.

\section{POCD at 1 Week Post-extubation}

At 1 week post-extubation in group 0, 14 patients (64\%) had no POCD, 8 patients (36\%) had mild POCD. In group N, 17 patients $(80 \%)$ had no POCD and 4 patients (20\%) had mild POCD. Both the groups did not have any patient with severe POCD.

Even at 1 week, the difference has not been statistically significant between the groups (Tables $4 \mathrm{~A}$ and $\mathrm{B}$ ).

During this study, we noted that there was a decline in the MoCA scores taken preoperatively as well as postoperatively in both the groups. Although the intergroup difference was not statistically significant, the intragroup difference was found to be significant $(p<0.001)$ in both the groups.

In a study conducted by Kara et al., ${ }^{4}$ the preoperative mean MoCA scores were comparable between the groups that received NIRS monitoring and the group that did not receive NIRS monitoring. In their study they noted that the decrease in post operative mean MOCA scores was not significant in the group that received NIRS monitoring and was significant in the 
Table 2: Other demographic parameters between the study group and the control group

\begin{tabular}{|c|c|c|c|c|c|c|}
\hline & & \multicolumn{2}{|c|}{ Groups } & \multirow[b]{2}{*}{ Total } & \multicolumn{2}{|c|}{ Chi-square test } \\
\hline & & Non-NIRS & NIRS & & Chi-square value & $p$ value \\
\hline \multirow[t]{4}{*}{ Sex } & $\mathrm{F}$ & 9 & 9 & 18 & 0.02 & 0.90 (NS) \\
\hline & & $40.9 \%$ & $42.9 \%$ & $41.9 \%$ & & \\
\hline & M & 13 & 12 & 25 & & \\
\hline & & $59.1 \%$ & $57.1 \%$ & $58.1 \%$ & & \\
\hline \multirow[t]{6}{*}{ Education } & Below metric & 14 & 13 & 27 & - & 1.00 (NS) \\
\hline & & $63.6 \%$ & $61.9 \%$ & $62.8 \%$ & & \\
\hline & Graduate & 3 & 4 & 7 & & \\
\hline & & $13.6 \%$ & $19.0 \%$ & $16.3 \%$ & & \\
\hline & PU & 5 & 4 & 9 & & \\
\hline & & $22.7 \%$ & $19.0 \%$ & $20.9 \%$ & & \\
\hline \multirow[t]{4}{*}{ HTN } & - & 9 & 10 & 19 & 0.20 & 0.66 (NS) \\
\hline & & $40.9 \%$ & $47.6 \%$ & $44.2 \%$ & & \\
\hline & + & 13 & 11 & 24 & & \\
\hline & & $59.1 \%$ & $52.4 \%$ & $55.8 \%$ & & \\
\hline \multirow[t]{4}{*}{ DM } & - & 11 & 15 & 26 & 2.06 & 0.15 (NS) \\
\hline & & $50.0 \%$ & $71.4 \%$ & $60.5 \%$ & & \\
\hline & + & 11 & 6 & 17 & & \\
\hline & & $50.0 \%$ & $28.6 \%$ & $39.5 \%$ & & \\
\hline \multirow[t]{4}{*}{ Smoking } & - & 17 & 17 & 34 & - & 1.00 (NS) \\
\hline & & $77.3 \%$ & $81.0 \%$ & $79.1 \%$ & & \\
\hline & + & 5 & 4 & 9 & & \\
\hline & & $22.7 \%$ & $19.0 \%$ & $20.9 \%$ & & \\
\hline \multirow[t]{4}{*}{ COPD } & - & 19 & 17 & 36 & - & 0.70 (NS) \\
\hline & & $86.4 \%$ & $81.0 \%$ & $83.7 \%$ & & \\
\hline & + & 3 & 4 & 7 & & \\
\hline & & $13.6 \%$ & $19.0 \%$ & $16.3 \%$ & & \\
\hline \multirow[t]{4}{*}{ Renal insufficiency } & - & 21 & 19 & 40 & - & 0.61 (NS) \\
\hline & & $95.5 \%$ & $90.5 \%$ & $93.0 \%$ & & \\
\hline & + & 1 & 2 & 3 & & \\
\hline & & $4.5 \%$ & $9.5 \%$ & $7.0 \%$ & & \\
\hline \multirow[t]{4}{*}{$\mathrm{F} / \mathrm{H} / \mathrm{O} C V D$} & - & 21 & 20 & 41 & - & 1.00 (NS) \\
\hline & & $95.5 \%$ & $95.2 \%$ & $95.3 \%$ & & \\
\hline & + & 1 & 1 & 2 & & \\
\hline & & $4.5 \%$ & $4.8 \%$ & $4.7 \%$ & & \\
\hline \multirow[t]{4}{*}{ Carotid lesion (>70\%) } & $B / L$ & 1 & 1 & 2 & - & 1.00 (NS) \\
\hline & & $4.5 \%$ & $4.8 \%$ & $4.7 \%$ & & \\
\hline & $\mathrm{U} / \mathrm{L}$ & 21 & 20 & 41 & & \\
\hline & & $95.5 \%$ & $95.2 \%$ & $95.3 \%$ & & \\
\hline
\end{tabular}

Fisher's exact test

$p<0.05$, statistically significant; $p>0.05$, nonsignificant, NS

Table 3: Intraoperative variables between the study and control groups

\begin{tabular}{|c|c|c|c|c|c|c|c|c|c|c|}
\hline & \multirow[b]{2}{*}{ Group } & \multirow[b]{2}{*}{$N$} & \multirow[b]{2}{*}{ Mean } & \multirow[b]{2}{*}{$S D$} & \multirow{2}{*}{$\begin{array}{l}\text { Mean } \\
\text { difference }\end{array}$} & \multicolumn{2}{|c|}{$95 \% \mathrm{Cl}$ of the difference } & \multirow[b]{2}{*}{$t$} & \multirow[b]{2}{*}{$d f$} & \multirow[b]{2}{*}{$p$ value } \\
\hline & & & & & & Lower & Upper & & & \\
\hline \multirow[t]{2}{*}{ Time taken (Min) } & Non NIRS & 22 & 74.77 & 13.84 & 0.01 & -9.71 & 9.73 & 0.002 & 41 & 1.00 (NS) \\
\hline & NIRS & 21 & 74.76 & 17.57 & & & & & & \\
\hline \multirow[t]{2}{*}{ No. of vessels grafted } & Non NIRS & 22 & 3.05 & 0.49 & -0.002 & -0.33 & 0.33 & -0.01 & 41 & 0.99 (NS) \\
\hline & NIRS & 21 & 3.05 & 0.59 & & & & & & \\
\hline
\end{tabular}

Independent sample $t$ test

$p<0.05$ statistically significant, $p>0.05$ non signifiant, NS 
Table 4A: MoCA scores

\begin{tabular}{|c|c|c|c|c|c|c|c|c|c|c|}
\hline & \multirow[b]{2}{*}{ Group } & \multirow[b]{2}{*}{$N$} & \multirow[b]{2}{*}{ Mean } & \multirow[b]{2}{*}{$S D$} & \multirow{2}{*}{$\begin{array}{l}\text { Mean } \\
\text { difference }\end{array}$} & \multicolumn{2}{|c|}{$95 \% \mathrm{Cl}$ of the difference } & \multirow[b]{2}{*}{$t$} & \multirow[b]{2}{*}{$d f$} & \multirow[b]{2}{*}{$p$ value } \\
\hline & & & & & & Lower & Upper & & & \\
\hline \multirow{2}{*}{$\begin{array}{l}\text { Preop MoCA } \\
\text { score }\end{array}$} & Non-NIRS & 22 & 28.09 & 1.74 & 0.09 & -0.98 & 1.16 & 0.17 & 41 & 0.87 (NS) \\
\hline & NIRS & 21 & 28.00 & 1.73 & & & & & & \\
\hline \multirow{2}{*}{$\begin{array}{l}\text { MoCA } 1 \text { hour } \\
\text { post-ex }\end{array}$} & Non-NIRS & 22 & 24.73 & 2.91 & 0.16 & -1.36 & 1.67 & 0.21 & 41 & 0.84 (NS) \\
\hline & NIRS & 21 & 24.57 & 1.86 & & & & & & \\
\hline \multirow{2}{*}{$\begin{array}{l}\text { MoCA } 24 \text { hours } \\
\text { post-ex }\end{array}$} & Non-NIRS & 22 & 25.95 & 2.55 & 0.24 & -1.08 & 1.56 & 0.37 & 41 & 0.72 (NS) \\
\hline & NIRS & 21 & 25.71 & 1.62 & & & & & & \\
\hline \multirow{2}{*}{$\begin{array}{l}\text { MoCA } 1 \text { week } \\
\text { post-ex }\end{array}$} & Non-NIRS & 22 & 26.68 & 2.57 & -0.37 & -1.72 & 0.99 & -0.55 & 41 & 0.59 (NS) \\
\hline & NIRS & 21 & 27.05 & 1.72 & & & & & & \\
\hline
\end{tabular}

Independent sample $t$ test

$p<0.05$, statistically significant; $p>0.05$, nonsignificant, NS

Table 4B: MoCA scores

\begin{tabular}{lllllll}
\hline Group & & $N$ & Mean & Std. deviation & $F$ & $p$ value \\
\hline Non NIRS & Preop MoCA score & 22 & 28.09 & 1.74 & 38.03 & $<0.001$ \\
& MoCA 1 hour post-ex & 22 & 24.73 & 2.91 & & \\
& MoCA 24 hours post-ex & 22 & 25.95 & 2.55 & & \\
\multirow{2}{*}{ NIRS } & MoCA 1 week post-ex & 22 & 26.68 & 2.57 & \multirow{2}{*}{0.62} & $<0.001$ \\
& Preop MoCA score & 21 & 28.00 & 1.73 & & \\
& MoCA 1 hour post-ex & 21 & 24.57 & 1.86 & & \\
& MoCA 24 hours post-ex & 21 & 25.71 & 1.62 & & \\
& MoCA 1 week post-ex & 21 & 27.05 & 1.72 & & \\
\hline
\end{tabular}

Repeated measures analysis of variance (ANOVA). $p<0.05$, statistically significant; $p>0.05$, nonsignificant, NS

Table 5: Secondary outcomes between the groups

\begin{tabular}{|c|c|c|c|c|c|c|c|c|c|c|}
\hline & \multirow[b]{2}{*}{ Group } & \multirow[b]{2}{*}{$N$} & \multirow[b]{2}{*}{ Mean } & \multirow[b]{2}{*}{$S D$} & \multirow{2}{*}{$\begin{array}{l}\text { Mean } \\
\text { difference }\end{array}$} & \multicolumn{2}{|c|}{ 95\% Cl of the difference } & \multirow[b]{2}{*}{$t$} & \multirow[b]{2}{*}{$d f$} & \multirow[b]{2}{*}{$p$ value } \\
\hline & & & & & & Lower & Upper & & & \\
\hline \multirow[t]{2}{*}{ Time taken (Min) } & Non-NIRS & 22 & 74.77 & 13.84 & 0.01 & -9.71 & 9.73 & 0.002 & 41 & 1.00 (NS) \\
\hline & NIRS & 21 & 74.76 & 17.57 & & & & & & \\
\hline \multirow[t]{2}{*}{ No. of vessels grafted } & Non-NIRS & 22 & 3.05 & 0.49 & -0.002 & -0.33 & 0.33 & -0.01 & 41 & 0.99 (NS) \\
\hline & NIRS & 21 & 3.05 & 0.59 & & & & & & \\
\hline \multirow[t]{2}{*}{ Duration of ICU stay (days) } & Non-NIRS & 22 & 5.91 & 1.38 & 0.39 & -0.39 & 1.16 & 1.00 & 41 & 0.32 (NS) \\
\hline & NIRS & 21 & 5.52 & 1.12 & & & & & & \\
\hline Time for extubation (hour) & Non-NIRS & 22 & 3.52 & 0.66 & 0.17 & -0.29 & 0.62 & 0.74 & 41 & 0.47 (NS) \\
\hline
\end{tabular}

Independent sample $t$ test. $p<0.05$, statistically significant; $p>0.05$, nonsignificant, NS

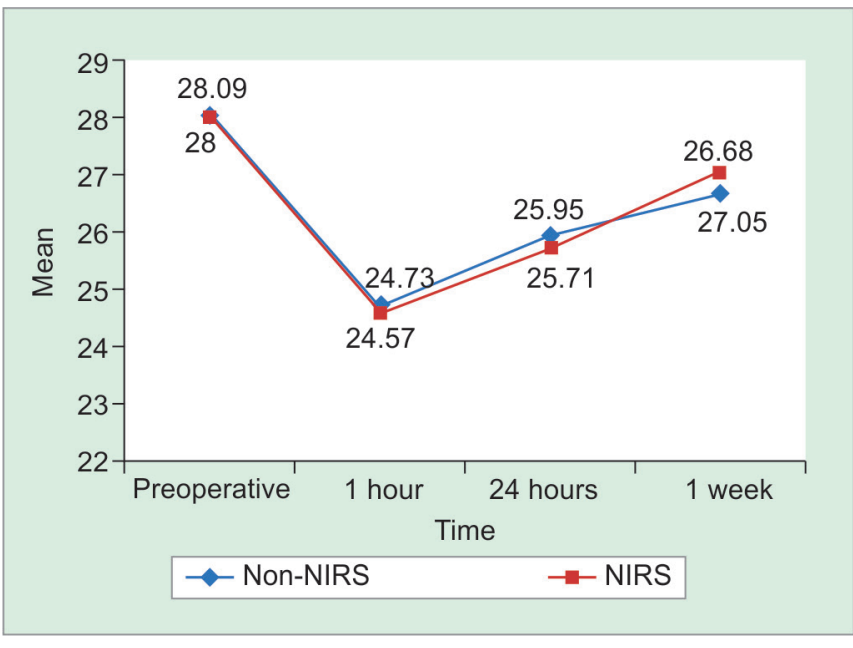

Fig. 1: MoCA scores preoperative, 1 hour, 24 hours, 1 week postextubation group that did not receive NIRS monitoring and subsequent management. One major difference between the study conducted by Kara et al. ${ }^{4}$ and the present study is that they had performed the study on patients who underwent on-pump CABG, while the present study was conducted on patients who underwent OPCAB. One possible explanation for the difference in their study and ours is that probably NIRS monitoring and management have a better utility in preventing POCD in patients undergoing on-pump CABG. On-pump CABG has multiple mechanisms which could lead to POCD like the presence of gaseous microemboli, aortic cross-clamping, etc. However, more studies are needed to make a recommendation on the routine use of NIRS in patients undergoing on-pump CABG even in the presence of asymptomatic carotid artery disease.

In a study conducted by Jetté et al., ${ }^{5}$ the POCD was as high as $80 \%$ at $4-7$ days after surgery. This is a contrasting result compared to our study. In our study, the occurrence of POCD was 33\% in the non-NIRS group and $20 \%$ in the NIRS group at 7 days. The possible 
explanation for this discrepancy is that the median age in their study was $69.72 \pm 4.57$. In our study, the median age was 60 years. In their study, they concluded that the age $>65$ years correlated well with the occurrence of early and late POCD. Moreover, in their sample, 46 patients out of 61 had undergone on-pump CABG. These results suggest that since the occurrence of POCD is higher in patients $>65$ years and lesser in patients who are less than 60 years, NIRS monitoring may have a better application in elderly patients. Also, since a majority of the patients underwent on-pump CABG, NIRS monitoring may be more useful in patients undergoing on-pump CABG. This is in agreement with the results obtained in the study conducted by Kara et al. ${ }^{4}$ Another possible reason for this discrepancy was that the tests used to assess POCD were different from the study conducted by Kara et al. ${ }^{4}$ and the present study.

Reents et al. $^{6}$ in their study have concluded that intraoperative regional cerebral oxygen saturation $\left(\mathrm{ScO}_{2}\right)$ as assessed by near-infrared spectroscopy with the INVOS 4100 device is not predictive for postoperative cognitive performance in patients undergoing CABG with cardiopulmonary bypass. This study had certain similarities with our study: the median age of the patients in their study was similar to ours (60 years). The occurrence of POCD obtained in their study despite using a battery of 5 neuropsychological tests was 34\% which was in agreement with ours. Their result was a stark contrast to certain studies which have found an association between low cerebral oxygenation and poorer cognitive outcome in patients undergoing cardiac operation with CPB. ${ }^{7}$ However, they have argued that those studies that found a correlation used the mini-mental state evaluation which is a crude instrument. Apart from that, they had used a different NIRS monitor with a different algorithm. Another reason the authors quote is that there is no regional saturation value that is critical of postoperative brain dysfunction. Available literature defines a cutoff of regional cerebral oxygen saturation $\left(\mathrm{rSO}_{2}\right)<50 \%$ or a relative decrease $>20 \%$ from baseline. ${ }^{8}$ Despite having patients with significant cerebral desaturation, they did not have a larger incidence of POCD. This is because the cutoff value of $\mathrm{rSO}_{2}$ for critical desaturation has not been defined.

Apart from these, we also assessed the secondary outcomes. The mean time taken for extubation was found to be 3.52 hours in the non-NIRS group and 3.36 hours in the NIRS group. This difference was not statistically significant (Table 5).

The mean duration of intensive care unit stay was 5.91 days in the non-NIRS group and 5.52 days in the NIRS group. This difference too was not statistically significant. These results are similar to those obtained by Kara et al. ${ }^{4}$

One of the limitations of the study was that the follow-up period was for a week. Cognitive dysfunction has been reported in approximately $50 \%$ of patients at discharge, $36 \%$ at 6 weeks, $26-33 \%$ at 1 year, and $42 \%$ at 5 years., ${ }^{9,10}$

Late-onset POCD was not a part of this study. Another drawback is the upper limit of the cutoff age which was taken as 70 years. Increasing the upper limit for age would have probably yielded a positive result.

\section{Conclusion}

The application of the NIRS monitor and subsequent management does not statistically decrease the occurrence of early POCD or its severity in patients with asymptomatic carotid artery undergoing $O P C A B$. It does not reduce the time taken for extubation or the duration of ICU stay. This has been demonstrated in our study.

\section{References}

1. Newman MF, Mathew JP, et al. Central nervous system injury associated with cardiac surgery. Lancet 2006;368:694-703. DOI: 10.1016/S0140-6736(06)69254-4.

2. Bekker AY, Weeks EJ. Cognitive function after anaesthesia in the elderly. Best Pract Res Clin Anaesthesiol 2003;17:259-272.

3. Mathiesen EB, Johnsen SH. Ultrasonographic measurements of subclinical carotid atherosclerosis in prediction of ischemic stroke. Acta Neurol Scand Suppl 2009;189:68-72. DOI: 10.1111/j.16000404.2009.01210.x.

4. Kara I, Erkin A, et al. The Effects of Near-Infrared Spectroscopy on the Neurocognitive Functions in the Patients Undergoing Coronary Artery Bypass Grafting with Asymptomatic Carotid Artery Disease: A Randomized Prospective Study. Ann Thorac Cardiovasc Surg 2015;21:544-550. DOI: 10.5761/atcs.oa.15-00118.

5. Jetté EDT, Dupuis G, et al. Relationship between Cerebral Oxygen Saturation Changes and Postoperative Cognitive Dysfunction in Elderly Patients after Coronary Artery Bypass Graft Surgery. J Cardiothorac Vasc Anesthesia 2011;25:95-104. DOI: 10.1053/j.jvca.2010.03.019.

6. Reent $W$, Muellges $W$, et al. Cerebral oxygen saturation assessed by near-infrared spectroscopy during coronary artery bypass grafting and early postoperative cognitive function. Ann Thorac Surg 2002;74:109-114. DOI: 10.1016/S0003-4975(02)03618-4.

7. Nollert G, Möhnle P, et al. Postoperative neuropsychological dysfunction and cerebral oxygenation during cardiac surgery. Thorac Cardiovasc Surg 1995;43:260-264. DOI: 10.1055/s-2007-1013224.

8. Cho H, Nemoto EM, et al. Cerebral monitoring by means of oxymetriy and somatosensory evoked potentials during carotid endarterectomy. J Neurosurg 1998;89:533-538. DOI: 10.3171/jns.1998.89.4.0533.

9. Newman MF, Kirchner JL, et al. Longitudinal assessment of neurocognitive function after coronary artery bypass surgery. $\mathrm{N}$ Engl J Med 2001;344:395-402. DOI: 10.1056/NEJM200102083440601.

10. Van Dijk D, Jansen EW, et al. Cognitive outcome after off-pump and on-pump coronary artery bypass graft surgery: a randomized trial. JAMA 2002;287:1405-1412. DOI: 10.1001/jama.287.11.1405. 